\title{
Prevalence of Factor V Leiden GI69IA and Prothrombin G20210A Gene Mutation Among Pregnant Women: Experience from a Multi-Center Study in Nigeria
}

\author{
Sarah O John-Olabode (ID) \\ Kehinde S Okunade (D) ${ }^{2}$ \\ Ayorinde James ${ }^{3}$ \\ Gbenga Olorunfemi $\mathbb{D D}^{4}$ \\ Obiefuna I Ajie \\ Akinniyi A Osuntoki ${ }^{6}$ \\ Alani S Akanmu' \\ 'Department of Hematology and Blood \\ Transfusion, College of Medicine, \\ University of Lagos, Lagos, Nigeria; \\ ${ }^{2}$ Department of Obstetrics and \\ Gynecology, College of Medicine, \\ University of Lagos, Lagos, Nigeria; \\ ${ }^{3}$ Department of Biochemistry and \\ Nutrition, Nigerian Institute of Medical \\ Research, Lagos, Nigeria; ${ }^{4}$ Division of \\ Epidemiology and Biostatistics, School of \\ Public Health, University of Witwatersrand, \\ Johannesburg, South Africa; ${ }^{5}$ Department \\ of Clinical Pathology, College of Medicine, \\ University of Lagos, Lagos, Nigeria; \\ ${ }^{6}$ Department of Biochemistry, College of \\ Medicine, University of Lagos, Lagos, \\ Nigeria
}

\begin{abstract}
Introduction: Inherited thrombophilia and venous thromboembolism (VTE) have been closely linked to adverse pregnancy outcomes such as preeclampsia/eclampsia contributing to increased maternal and perinatal morbidity and mortality. There is, however, little genetic data from Africa including Nigeria that explores the prevalence of common VTE genetic risk markers such as factor V Leiden mutation (FVL G1691A) and prothrombin gene mutation (F2 G20210A) among pregnant women in Nigeria.

Purpose: To determine the prevalence and distribution of FVL G1691A and F2 G20210A in pregnant women in Lagos, Nigeria.

Patients and Methods: This hospital-based cross-sectional pilot study was conducted among pregnant women between 1 July 2019 and 31 August 2020. The genotype of interest was determined through amplification by polymerase chain reaction using G1691A of FV and prothrombin A20210G specific primers. Descriptive data were presented using Stata version 15 (Stata Corp) statistical software.

Results: Of the 400 recruited participants, 397 and 389 samples were successfully processed for FVL G1691A and F2 G20210A mutations, respectively. Three participants had FVL heterozygous mutation; thus, the prevalence of heterozygous mutation of FVL among the study participants was $0.76 \%, 95 \%$ CI: $0.002-0.023 \%, n=3 / 397$. There was no F2 G20210A mutation detected among the study participants.

Conclusion: This study indicates that screening for factor V Leiden mutation and prothrombin gene mutation in pregnancy might not be of any clinical significance among Nigerian women. However, carrying out a genome-wide associated study is recommended to determine the true impact of these two common inherited thrombophilias in this population.
\end{abstract}

Keywords: factor V Leiden G1691A, prothrombin G20210A gene mutation, factor 2, factor $\mathrm{V}$, preeclampsia, venous thromboembolism

\section{Introduction}

Pregnant women with inherited thrombophilia have an over 50\% increased risk of developing venous thromboembolism (VTE); ${ }^{1}$ VTE has been attributed to $9-14 \%$ of maternal deaths. ${ }^{2,3}$ Inherited thrombophilia and VTE have been closely linked to various adverse pregnancy outcomes contributing to increased maternal and perinatal morbidity and mortality. ${ }^{4,5}$ One such adverse pregnancy outcome is preeclampsia/
Correspondence: Sarah O John-Olabode Department of Hematology and Blood Transfusion, College of Medicine,

University of Lagos, Lagos, Nigeria

Tel +2348096608I52

Email sarahajibola@yahoo.com 
eclampsia (PET), which is responsible for $11 \%$ of maternal deaths in Nigeria. ${ }^{6}$ Indeed, PET is one of the five leading causes of maternal mortality in Nigeria. ${ }^{7}$ The most frequent inherited thrombophilias evaluated for VTE are notably factor V Leiden mutation (FVL G1691A) and prothrombin gene mutation (F2 G20210A). The prevalence of these two mutations is $3-15 \%$ in Caucasians but is assumed to be rare in other ethnic populations. There is, however, little genetic data from many parts of Africa, including Nigeria the country that contributes the largest proportion (19\%) of the burden of maternal mortality (MM) worldwide and $29 \%$ of the total MM from Sub-Saharan African. ${ }^{8,9}$ This study therefore evaluated the prevalence of these common VTE genetic risk markers among pregnant women in Lagos, Nigeria.

\section{Patients and Methods}

\section{Study Setting}

This cross-sectional multi-centre pilot study was conducted among 400 pregnant women receiving obstetric care at the antenatal clinics of the Lagos University Teaching Hospital (LUTH) and Randle General Hospital, Lagos over a period of 13 months (1 July 2019 to 31 August 2020).

This study was approved by the College of Medicine, University of Lagos Health Research Ethics Committee (Approval number: HREC/15/04/2015).

\section{Study Population}

Eligible participants were consecutively consenting pregnant women aged 15-49 years who registered for antenatal care in the two participating hospitals. Pregnant women below the age of 18 years were regarded as emancipated minors. "Emancipated minor" is a person who is not of legal age to give consent (below 18 years of age in Nigeria) for a research study but who by marriage, pregnancy, being the mother of a child whether married or not or has left home and is self-sufficient can be allowed to give consent legally. Written informed consent was obtained from each participant following an explanation of the nature and purpose of the study and before recruitment.

\section{Data Collection}

A structured interviewer-administered questionnaire was used to collect data on sociodemographic characteristics and obstetric history. Whole blood samples were collected from each study participant in ethylenediaminetetraacetic acid (EDTA) tubes. To improve the deoxyribonucleic acid (DNA) yield, white cells were separated from whole blood by centrifugation to produce buffy coats following the Qiagen protocol. ${ }^{10}$

\section{Determination of Genotype Genomic DNA Extraction}

The extraction of DNA was performed at the Nigerian Institute of Medical Research, Lagos (NIMR) using a Presto $^{\mathrm{TM}}$ Well Blood Genomic DNA Extraction kit (Geneaid Biotech GB, Taiwan) following the vacuum protocol. Briefly, $20 \mu \mathrm{L}$ of protease was added to the bottom of each microtube and $200 \mu \mathrm{L}$ of buffy coats were carefully added without touching the rims of the microtubes. To each microtube $200 \mu \mathrm{L}$ of lysis buffer (GB Buffer) was added, mixed thoroughly for 15 seconds, and incubated at $70^{\circ} \mathrm{C}$ for 10 minutes. Absolute ethanol $(200 \mu \mathrm{L})$ was added to each sample and carefully mixed by pipetting up and down 5 times. Lysates were transferred to the Presto $^{\mathrm{TM}}$ gDNA 96-well binding plate. A vacuum pressure of 15 inches $\mathrm{Hg}$ was applied until the lysates passed through the binding plate into the collection tube leaving nucleic acids abound to the plate. The binding plate was washed twice with 400 and $600 \mu \mathrm{L}$ of wash buffer successively, with a vacuum pressure of 15 inches $\mathrm{Hg}$ applied at each wash step. An additional 10 minutes of the vacuum pressure was added to the dry binding plate membrane. The Presto ${ }^{\mathrm{TM}}$ gDNA 96-well binding plate was removed from the assembled manifold, the nozzles were cleaned, and it was re-assembled over DNase/RNase free microtubes to collect eluted DNA using $200 \mu \mathrm{L}$ of preheated $\left(60^{\circ} \mathrm{C}\right)$ elution buffer $(10 \mathrm{mM}$ Tris- $\mathrm{HCl}, 1 \mathrm{mM}$ EDTA, pH8.0) from the binding plate. Eluted DNA were quantified using Nano Drop ${ }^{\mathrm{TM}} 2000$ (Thermo Fisher Scientific, USA) and stored at $-20^{\circ} \mathrm{C}$ prior to downstream applications.

\section{rhAmp SNP Assay Design}

Factor 2 (rs1799963) and factor V Leiden single nucleotide polymorphisms (SNPs) (rs6025) were selected from the dbSNP database and entered into the RNAase $\mathrm{H}$ amplification (rhAmp) Genotyping Design Tool (https://www.idtdna.com/site/order/designtool/index/) for biallelic blocked rhAmp primers conjugated with either FAM fluorophore (Allele Primer 1) or Yakima Yellow (Allele Primer 2), and a non-fluorogenic locus rhAmp primer (Table 1). Synthetic gBlocks ${ }^{\circledR}$ Gene Fragments 
Table I rhAmp SNP Assay Design

\begin{tabular}{|l|l|l|l|}
\hline Gene Name & SNP ID & Primer Name & Sequence \\
\hline F5 & rs6025 & $\begin{array}{l}\text { Allele Primer I } \\
\text { Allele Primer 2 } \\
\text { Locus Primer }\end{array}$ & $\begin{array}{l}\text { /rhAmp-F/AAGGACAAAATACCTGTATTCCTCrGCCTG/GTI } \\
\text { /rhAmp-Y/AAGGACAAAATACCTGTATTCCTTrGCCTG/GTI/ } \\
\text { GCCCAGTGCTTAACAAGACCATrACTAC/GT4/ }\end{array}$ \\
\hline F2 & rs l799963 & $\begin{array}{l}\text { Allele Primer I } \\
\text { Allele Primer 2 } \\
\text { Locus Primer }\end{array}$ & $\begin{array}{l}\text { /rhAmp-F/CCAATAAAAGTGACTCTCAGCGrAGCCT/GT3/ } \\
\text { /rhAmp-Y/CCAATAAAAGTGACTCTCAGCArAGCCT/GT3/ } \\
\text { GCAGCTGCCCATGAATAGCArCTGGG/GT4 }\end{array}$ \\
\hline
\end{tabular}

(Integrated DNA Technologies, https://www.idtdna.com/ pages/products/genes/gblocks-gene-fragments) were used as known genotype controls (Supplementary Material). gBlocks Gene Fragments representing the wild type and mutant allele were mixed together in an equal molar ratio, representing the heterozygous genotype.

\section{rhAmp SNP Assay}

Purified genomic DNA samples were normalized with TE (Tris-EDTA) buffer ( $\mathrm{pH} 7.5$ ) to a concentration of $3 \mathrm{ng} / \mu \mathrm{L}$. Synthetic gene templates for the reference (Allele 1) and alternate alleles (Allele 2) were diluted to 500 copies $/ \mu \mathrm{L}$, while the heterozygous control was a pool of equal volume of the controls for each allele. rhAmp Genotyping mastermix and reporter mix were combined at a volume ratio of 20:1 in a new tube. A $5 \mu \mathrm{L}$ assay reaction was carried out in a tube containing $2.56 \mu \mathrm{L}$ combined master mix and reporter mix, $0.25 \mu \mathrm{L}$ rhAmp SNP assay, $0.1 \mu \mathrm{L}$ Nuclease free water, and $2 \mu \mathrm{L}(6 \mathrm{ng})$ of template DNA or 1000 copies of synthetic gene controls. Thermal cycling was done on a CFX96 Touch Real-Time PCR Detection System (BioRad Laboratories 3, Marnes-la-Coquette, France) using the cycling profile enzyme activation at $95^{\circ} \mathrm{C}$ for $10 \mathrm{mins}$; and a $40 \mathrm{X}$ repeated cycle of denaturation at $95^{\circ} \mathrm{C}$ for 10 secs; annealing at $60^{\circ} \mathrm{C}$ for $30 \mathrm{secs}$, and extension at $68^{\circ} \mathrm{C}$ for 20 secs. Signal was captured at the extension step and the FAM channel was assigned to the reference allele while the VIC channel was assigned to the alternate allele. An allelic discrimination plate was set-up and identified using Bio-Rad analysis software. Automatic allele calls were reviewed and converted into genotypes.

\section{Definition of Study Endpoints}

The study endpoint was the prevalence of thrombophilic gene mutation among pregnant women within the age group, 15 to 49 years. Each single nucleotide polymorphism (SNP) result was classified as: homozygous $\mathrm{A} / \mathrm{A}$ (mutant/mutant), heterozygous A/G (mutant/wild type) or normal $\mathrm{G} / \mathrm{G}$ (wild type/wild type). ${ }^{11}$

\section{Data Analysis}

Stata version 15 (Stata Corp) statistical software was used for data analysis. The sociodemographic and clinical characteristics of the participants were described. Categorical variables were presented as frequencies, percentages and charts, while normally distributed continuous variables were presented as mean \pm standard deviation and nonnormally distributed continuous variables were presented as median (interquartile range). Prevalence of thrombophilic polymorphisms among the study participants was determined with a $95 \%$ confidence interval.

\section{Results}

The sociodemographic characteristics of the 400 pregnant women who participated in the study are presented in Table 2. The mean age and median parity were $31.9 \pm$ 5.2 years and $1(0-2)$, respectively.

Detailed information about the two polymorphisms of interest is presented in Table $3 .^{12}$ Of the 400 samples collected from the study participants, 14 (3F5, 11F2)

Table 2 Sociodemographic Characteristics of Study Participants

\begin{tabular}{|l|l|}
\hline Characteristics & N (\%) \\
\hline Age (Year \pm SD) & $31.9 \pm 5.2$ \\
\hline Gestational age (median, IQR) weeks & $20(I 7-26)$ \\
\hline Parity (median, IQR) & $\mathrm{I}(0-2)$ \\
\hline Primigravidae & $\mathrm{I} 10(27.5)$ \\
\hline Multigravida & $290(72.5)$ \\
\hline $\begin{array}{l}\text { Ethnicity } \\
\text { Igbo } \\
\text { Yoruba }\end{array}$ & $150(39.6)$ \\
Hausa & $225(59.4)$ \\
\hline
\end{tabular}


Table 3 Targeted Single Nucleotide Polymorphisms

\begin{tabular}{|l|l|l|l|l|l|}
\hline Polymorphism & rsSNP & Gene Name & Symbol & Protein Change & Gene Consequence \\
\hline 202 I0G-A & rsl799963 & Coagulation factor II, thrombin & F2 & None & 3 Prime UTR Variant \\
\hline FV Leiden & rs6025 & Coagulation factor V & F5 & R (Arg) > Q (GIn) & Missense Variant \\
\hline
\end{tabular}

Abbreviations: rs, reference single nucleotide polymorphism; UTR, untranslated region; Arg, arginine; Gln, glutamine.

Table 4 Frequency of Normal and Mutant Genotypes in Study Population

\begin{tabular}{|l|l|l|l|}
\hline Polymorphism & $\begin{array}{l}\text { Normal } \\
(\%)\end{array}$ & $\begin{array}{l}\text { Heterozygote } \\
(\%)\end{array}$ & $\begin{array}{l}\text { Homozygote } \\
(\%)\end{array}$ \\
\hline F2 (n=389) & $389(100)$ & 0 & 0 \\
\hline FV (n=397) & $394(99.2)$ & $3(0.76)$ & 0 \\
\hline
\end{tabular}

Abbreviations: $\mathrm{F} 2$, factor II; FV, factor $\mathrm{V}$.

were not amplified successfully. The FVL heterozygous mutation was found in 3 of the 397 samples that amplified for FVL detection, thus the prevalence of heterozygous mutation of FV among the study participants was $0.76 \%$, 95\% CI: $0.002 \%-0.023 \%, n=3 / 397$ (Table 4).

In contrast, $\mathrm{F} 2 \mathrm{G} 20210 \mathrm{~A}$ mutation was not recorded in any of the 389 samples that amplified for F2 G20210A detection.

The presence of FVL mutation had no clinical significance in this population as the three participants who tested positive for FVL mutation had no prior history of adverse pregnancy outcomes and also recorded no complications in the index pregnancies (Table 5).

\section{Discussion}

Inherited thrombophilia polymorphisms have been linked with VTE and placenta mediated pregnancy complications that remain one of the major causes of perinatal and maternal morbidity and mortality in underdeveloped nations. ${ }^{13-22}$

There is limited information on the prevalence of inherited thrombophilias in Nigeria, and to the best of our knowledge this study is the first of its kind to determine the prevalence of rs6025 (FVL) and rs1799963 (F2) gene mutations in asymptomatic pregnant women whose thrombophilia status is unknown and the significance of screening for these inherited thrombophilias to aid clinical governance in our population.

Our study has revealed some key findings. First, we have shown that the prevalence of rs6025 (FVL) and rs1799963 (F2) mutation is very low in our study population. In this study, rs6025 (FVL) mutation was present in $0.76 \%$ of the study population, while rs1799963 (F2)
Table 5 Characteristics of Participants with FVL Heterozygote Mutation

\begin{tabular}{|l|l|l|l|}
\hline Characteristics & Participant A & Participant B & Participant C \\
\hline Age (years) & 35 & 27 & 31 \\
\hline Ethnicity & Yoruba & Yoruba & lgbo \\
\hline Blood group & O Positive & AB positive & O Positive \\
\hline $\begin{array}{l}\text { Hemoglobin } \\
\text { Genotype }\end{array}$ & AA & AA & AA \\
\hline Parity & 2 & I & 2 \\
\hline Birth weight (gm) & 3420 & 3100 & 2200,2500 \\
\hline Type of Pregnancy & Singleton & Singleton & Multiple \\
\hline Mode of delivery & $\begin{array}{l}\text { Normal } \\
\text { delivery }\end{array}$ & $\begin{array}{l}\text { Caesarean } \\
\text { section }\end{array}$ & $\begin{array}{l}\text { Caesarean } \\
\text { section }\end{array}$ \\
\hline Perinatal outcome & Alive & Alive & Alive \\
\hline
\end{tabular}

genetic mutation was not detected in any of the study participants. This finding is in agreement with previous reports that found a low incidence of FVL and F2 mutations in Africans. ${ }^{23-26}$ Despite a paucity of data in the variants of rs6025 and rs1799963 in studies involving pregnant women in Nigeria, we used information deposited in the 1000 genome browser of the National Centre for Biotechnology Information as a comparative control in investigating allelic variants in this study (https://www.ncbi.nlm.nih.gov/varia tion/tools/1000genomes). The Yoruba and Esan ethnic groups were captured in the 1000 genomes project and the minor allele frequencies (MAF) for both rs6025 (FVL) and rs 1799963 (F2) were reported to be $0 \%{ }^{27}$ In this study, MAF for rs6025 (FVL) was found to be $0.76 \%$, while that of rs1799963 remained at $0 \%$.

Another important finding of this study is corroboration of the fact that women who have inherited thrombophilia can have a problem-free pregnancy, as women who had heterozygous FVL mutation in this study had uneventful pregnancies with no peripartum complications. Similarly, Said et al reported no adverse pregnancy outcomes in the majority of subjects among a cohort of 
nulliparous women with inherited thrombophilia polymorphisms. ${ }^{28}$

The third key finding of this study was the ethnic variation in the prevalence of FVL mutation in participants who were heterozygotes for FVL mutation, as this mutation was found predominantly $(66.7 \%, n=2 / 3)$ among women from the Yoruba ethnic group in the Southwestern part of Nigeria. This may however not be out of place as the study was conducted in the Southwestern part of Nigeria that is inhabited mainly by the Yoruba ethnic population.

Though our data suggest that FVL and F2 gene mutations have low prevalence and therefore no risk factors that should be considered in our population, it is still possible that associations with other specific pregnancy complications, such as fetal growth restriction, stillbirth, placental abruption and thrombophilias, may be seen if a genome-wide associated study (GWAS) is conducted in the future. Our study had a few limitations. First, it was a hospital-based study, which thus limits generalization of the findings to a larger population. Second, there was limited power to make any inference from the findings. However, this is the first known attempt in Nigeria to determine the prevalence of rs6025 (FVL) and rs1799963 (F2) polymorphisms in pregnant women and to examine the possible effects of these mutations on pregnancy outcomes.

\section{Conclusion}

Our data revealed a very low prevalence of FVL G1691A and FII G20210A mutations among pregnant women in Lagos, Nigeria and also suggests that these particular inherited thrombophilias may be of minimal clinical significance among heterozygotes in pregnancy. However, this study has provided valuable information for conducting large cohort studies on these polymorphisms among pregnant women in Nigeria. This could inform future policies that might be useful in the prediction and prevention of VTE and other related placenta-mediated pregnancy complications in Nigerian women.

\section{Abbreviations}

VTE, venous thromboembolism; PET, preeclampsia; FVL, factor V Leiden; EDTA, ethylenediaminetetraacetic acid; DNA, deoxyribonucleic acid; rhAmp, RNAse $\mathrm{H}$ amplification; dbSNP, SNP database.

\section{Data Sharing Statement}

All data are available from the corresponding author on request. Supplementary data was submitted with this paper.

\section{Ethics Approval and Consent to Participate}

The study protocol was permitted by the Ethics Committee of the College of Medicine University of Lagos and adhered to the Declaration of Helsinki principles. Informed written consent was obtained from each subject.

\section{Acknowledgments}

The authors thank the physicians and patients who participated in the present study.

\section{Author Contributions}

SOJ conceptualized and designed the study and wrote the paper, AJ performed the genetic analysis and GO performed the statistical analysis, analyzed and interpreted the patient data. AAO and ASA both helped in the revision of the paper. KSO and OIA helped in the collection of the data, analyzed and interpreted the patient data and helped with revising the paper. All authors made substantial contributions to conception and design, acquisition of data, or analysis and interpretation of data; took part in drafting the article or revising it critically for important intellectual content; agreed to submit to the current journal; gave final approval of the version to be published; and agree to be accountable for all aspects of the work.

\section{Funding}

This research was supported by the Fogarty International Center of the National Institutes of Health under Award Number D43TW010134. The content is solely the responsibility of the authors and does not necessarily represent the official views of the National Institutes of Health.

\section{Disclosure}

The authors report no conflicts of interest in this work.

\section{References}

1. Myers B, Pavord S. Heritable thrombophilias: implications for pregnancy and current evidence for treatment. Obstetr Gynaecol. 2011;13:225-230. doi:10.1576/toag.13.4.225.27687

2. Centers for Disease Control and Prevention. Pregnancy mortality surveillance system; 2016 Available from: http://www.cdc.gov/repro ductivehealth/maternalinfanthealth/pmss.html. Accessed February 2, 2019. 
3. Say L, Chou D, Gemmill A. Global causes of maternal deaths: a WHO systematic analysis. Lancet Glob Health. 2014;2(6):e329e338. doi:10.1016/S2214-109X(14)70227-X

4. Kupferminc MJ. Thrombophilia and pregnancy. Reprod Biol Endocrinol. 2003;1:111. doi:10.1186/1477-7827-1-111

5. Robertson $\mathrm{L}$, Wu O, Langhorne $\mathrm{P}$, et al. Thrombophilia in pregnancy: a systematic review thrombosis: risk and economic assessment of thrombophilia screening (TREATS) study. Br J Haematol. 2006;132 (2):171-196. doi:10.1111/j.1365-2141.2005.05847.x

6. African Population and Health Research Center. Maternal health in Nigeria: facts and figures fact sheet June 2017. Adapted from the report: maternal health in Nigeria: a situation update; 2016. Available from: www.aphrc.org/publications/maternal-health-nigeria-situationupdate/. Accesed April 30, 2021.

7. Agan TU, Monjok E, Akpan UB, Omoronyia OE, Ekabua JE. Trend and causes of maternal mortality in a Nigerian Tertiary Hospital: a 5-year retrospective study (2010-2014) at the University of Calabar Teaching Hospital, Calabar, Nigeria. Open Access Maced J Med Sci. 2018;6(6):1153-1158. doi:10.3889/oamjms.2018.220

8. Hulley SB, Cummings SR, Browner WS, Grady D, Newman TB. Designing Clinical Research: An Epidemiologic Approach. 4th ed. Philadelphia, PA: Lippincott Williams \& Wilkins; 2013:Appendix $6 \mathrm{~B} ; 75$.

9. Nelen WLDM, Steegers EAP, Eskes TKAB, Blom HJ. Genetic risk factor for unexplained recurrent early pregnancy loss. Lancet Res Lett. 1997;350(9081):861. doi:10.1016/S0140-6736(97)24038-9

10. QIAGEN. QIAsymphony SP protocol sheet: DNA_Buffy_Coat_400_V6_DSP by Qiagen; 2019. Available from: www.qiagen.com. Accessed June 2, 2019.

11. Ghermann RB, Goodwin TM. Obstetric implications of activated protein C resistance and factor V Leiden mutation. Obstet Gynecol Surv. 2000;55(2):117-122. doi:10.1097/00006254-200002000-00026

12. Traven E, Ogrinc A, Kunej T. Initiative for standardization of reporting genetics of male infertility. Syst Biol Reprod Med. 2017;63:58-66. doi:10.1080/19396368.2016.1250181

13. Rey E, Kahn SR, David M, Shrier I. Thrombophilic disorders and fetal loss: a meta-analysis. Lancet. 2003;361:901-908. doi:10.1016/ S0140-6736(03)12771-7

14. Howley HE, Walker M, Rodger MA. A systematic review of the association between factor $\mathrm{V}$ Leiden or prothrombin gene variant and intrauterine growth restriction. Am J Obstet Gynecol. 2005;192:694-708. doi:10.1016/j.ajog.2004.09.011

15. Agorastos T, Karavida A, Lambropoulos A, et al. Factor V Leiden and prothrombin G20210A mutations in pregnancies with adverse outcome. J Matern Neonatal Med. 2002;12:267-273. doi:10.1080/ jmf.12.4.267.273
16. Benedetto C, Marozio L, Salton L, Maulà V, Chieppa G, Massobrio M. Factor V Leiden and factor II G20210A in preeclampsia and HELLP syndrome. Acta Obstet Gynecol Scand. 2002;81:1095-1100. doi:10.1034/j.1600-0412.2002.811201.x

17. Muetze S, Leeners B, Ortlepp JR, et al. Maternal factor V Leiden mutation is associated with HELLP syndrome in Caucasian women. Acta Obstet Gynecol Scand. 2008;87:635-642. doi:10.1080/ 00016340802112740

18. Nagy B, Tóth T, Rigó J, Karádi I, Romics L, Papp Z. Detection of factor V Leiden mutation in severe pre-eclamptic Hungarian women. Clin Genet. 1998;53:478-481. doi:10.1111/j.1399-0004.1998. tb02599.x

19. Mello G, Parretti E, Marozio L, et al. Thrombophilia is significantly associated with severe preeclampsia: results of a large-scale, case-controlled study. Hypertens 1979. 2005;46:1270-1274. doi:10.1161/01.HYP.0000188979.74172.4d.

20. Wang X, Bai T, Liu S, Pan H, Wang B. Association between thrombophilia gene polymorphisms and preeclampsia: a meta-analysis. PLoS One. 2014;9:e100789. doi:10.1371/journal.pone.0100789.

21. Dudding T, Heron J, Thakkinstian A, et al. Factor V Leiden is associated with pre-eclampsia but not with fetal growth restriction: a genetic association study and meta-analysis. $J$ Thromb Haemost. 2008;6:1868-1875. doi:10.1111/j.1538-7836.2008.03134.x

22. Lin J, August P. Genetic thrombophilias and preeclampsia: a meta-analysis. Obstet Gynecol. 2005;105:182-192. doi:10.1097/01. AOG.0000146250.85561.e9

23. Rees DC, Cox M, Clegg JB. World distribution of factor V Leiden. Lancet. 1995;346:1133-1134. doi:10.1016/S0140-6736(95)91803-5

24. Patel RK, Arya R. Venous thromboembolism: racial and ethnic influences. Therapy. 2008;5:169-175. doi:10.2217/14750708.5.2.169

25. Montagnana M, Favaloro EJ, Franchini M, Guidi GC, Lippi G. The role of ethnicity, age and gender in venous thromboembolism. J Thromb Thrombolysis. 2010;29(4):489-496. doi:10.1007/s11239009-0365-8

26. Hira B, Pegoraro RJ, Rom L, Moodley J. Absence of factor V Leiden, thrombomodulin and prothrombin gene variants in black south African women with pre-eclampsia and eclampsia. BJOG. 2003;110:327-328. doi:10.1046/j.1471-0528.2003.01090.x

27. National Centre for Biotechnology Information. 100 genome project; 2021. Available from: https:/www.ncbi.nlm.nih.gov/variation/tools/ 1000genomes. Accessed April 4, 2021.

28. Said JM, Higgins JR, Moses EK, et al. Inherited thrombophilia polymorphisms and pregnancy outcomes in nulliparous women. Obstet Gynecol. 2010;115:5-13. doi:10.1097/AOG.0b01 3e3181c68907
Journal of Blood Medicine

\section{Publish your work in this journal}

The Journal of Blood Medicine is an international, peer-reviewed, open access, online journal publishing laboratory, experimental and clinical aspects of all aspect pertaining to blood based medicine including but not limited to: Transfusion Medicine; Blood collection, Donor issues, Transmittable diseases, and Blood banking logistics; Immunohematology; Artificial and alternative blood based therapeutics; Hematology; Biotechnology/nanotechnology of blood related medicine; Legal aspects of blood medicine; Historical perspectives. The manuscript management system is completely online and includes a very quick and fair peer-review system. Visit http://www.dovepress.com/testimonials.php to read real quotes from published authors. 